\title{
Friction Stir Welding of EN 10130 Low Carbon Steel
}

\author{
Akbar Alimohamady*, Abbas Eghlimi**, Hosain Nourozi Foroshani***, \\ Mohamad Alipour Behzadi****, Javad Mohammadi*****, $\dagger$ and Masoud Kasiri Asgarani* \\ *Advanced Materials Research Center, Department of Materials Engineering, Islamic Azad University, \\ Najafabad, 8514143131, Iran \\ **Department of Materials Engineering, Isfahan University of Technology, Isfahan, 84156-83111, Iran \\ ***Mechanic Engineering Faculty, Polytechnic University, Tehran, 1591634311, Iran \\ ****Material Science and Engineering Department, Engineering Faculty, \\ Shahid Chamran University of Ahvaz, Ahvaz, 8315161357, Iran \\ *****Department of Materials Engineering, University of Windsor, Windsor, N9B3P4, Canada
}

†Corresponding author : mohammaj@uwindsor.ca

(Received July 22, 2019 ; Revised August 21, 2019 ; Accepted February 27, 2020)

\begin{abstract}
After evaluating the weldability of $1.5 \mathrm{~mm}$ thick EN 10130 steel sheets, the influence of friction stir welding parameters, i.e., rotation speed, tool advancing speed, pin diameter, and shoulder diameter on the properties of sound joints was examined. Using metallography, scanning electron microscope, tensile test, microhardness measurement, limiting dome height test, and forming limit diagrams, it was found that having a flawless joint requires the rotation and advancing speeds to be in the range of 500-1000 rpm and 30-160 mm. min ${ }^{-1}$, respectively. A design of experiment with 29 samples based on the Box-Behnken response surface methodology method with 5 center points was then utilized to maximize the tensile strength. Accordingly, the safe range and an optimized point for welding parameters were defined.
\end{abstract}

Key Words : Friction stir welding, Low carbon steel, DOE, RSM

\section{Introduction}

Among novel welding processes, friction stir welding (FSW) has received widespread attention from many in various industries, including automobile industry for joining steel and aluminum alloys ${ }^{1)}$. However, the major problem of sheets joined by FSW technique is the reduction in mechanical properties compared to base metal. This is usually due to the incorrect selection of welding parameters such as imprecise tool rotation speed, advancing speed, pin and shoulder diameters, tilt angle, preheat temperature, tool rotation direction (clockwise or counter clockwise), fixture and clamping system, tool geometry, etc. ${ }^{1-4)}$. A flawless joint can only be obtained by selecting welding parameters in a limited range; otherwise, mechanical properties will suffer significantly ${ }^{5,6}$. However, selection of these parameters is highly dependent on sheet thickness and material type making each FSW process unique ${ }^{1,7)}$. Jafarzadegan et al. ${ }^{8)}$ investigated FSW of St37 steel and 304 stainless steel technique in constant advancing speed and 400 $\mathrm{rpm}$ and $800 \mathrm{rpm}$ tool rotation speeds. They found that the sample welded with lower tool rotation speed had higher elongation and lower strength. Moreover, tungsten carbide (WC) particles were observed in the cross-section of the specimen welded by a higher rotation speed resulting in a lower joint ductility. Ghafarpour et al. ${ }^{2)}$ joined 5083-H12 and 6061-T6 aluminum alloy sheets by FSW and optimized welding parameters including tool rotation speed, advancing speed, pin diameter, and shoulder diameter using design of experiment (DOE). They also determined a safe range for every parameter by performing limiting dome height (LDH) tests on the welded specimens and could maximize the formability of welded joints by optimizing the welding 
parameters. Yazdipour et al. ${ }^{9)}$ joined 5083-H321 aluminum alloy and 316L steel sheets by FSW technique. They realized that by at higher advancing speeds, defects form in the cross-section of the steel sheet leading to a decrease in the joint strength. Ramesh et al. ${ }^{10)}$ welded high strength low alloy (HSLA) steel sheets by FSW and studied the relationship between microstructure and tensile strength. They discovered that high advancing speeds decrease the join strength significantly. Cho et al. ${ }^{11)}$ successfully welded type 409 ferritic steel by FSW. They found that stir zone microstructure is completely fine-grained and has very high strength which is due to recrystallization of shear deformation and evaluated temperature.

EN 10130 sheets are used widely in automobiles bodies $^{12)}$; thus it is required to have a great understanding of their weldability using conventional methods such as FSW. Following the evaluation of the weldability of EN 10130 joints using FSW in a previous work ${ }^{13}$ ), this paper investigates the effective parameters, i.e. tool rotation speed, advancing speed, pin diameter, and shoulder diameter and optimizes them using DOE. Then, the structure-property relationship is discussed in the EN 10130 sheets welded by optimum parameters.

In the present study, after evaluating the weldability of EN 10130 joints using FSW, the effective parameters, i.e. tool rotation speed, advancing speed, pin diameter, and shoulder diameter, were optimized using DOE. Then, microstructure, mechanical properties and joint ductility of EN 10130 sheets welded by optimum parameters were studied.

\section{Experimental procedure}

In order to prepare specimens, FSW process with different parameters was performed on EN 10130 rolled steel sheets (168 MPa yield strength and $315 \mathrm{MPa}$ tensile strength) with $1.5 \mathrm{~mm}$ thickness and the chemical composition given in Table 1. Tungsten carbide tool with conical pin (Fig. 1) was used for welding. After FSW process, samples were ground and etched in $2 \%$ nital solution for $20 \mathrm{~s}$ for metallography examination. Microstructural evaluations were carried out by optical microscope and VEGA/TESCAN-XMU scanning electron microscope (SEM) at $20.00 \mathrm{kV}$ high voltage. Tensile test samples were prepared based on ASTM E8 standard. Measurement of Vickers microhardness was performed under $100 \mathrm{~g}$ load for $15 \mathrm{~s}$.

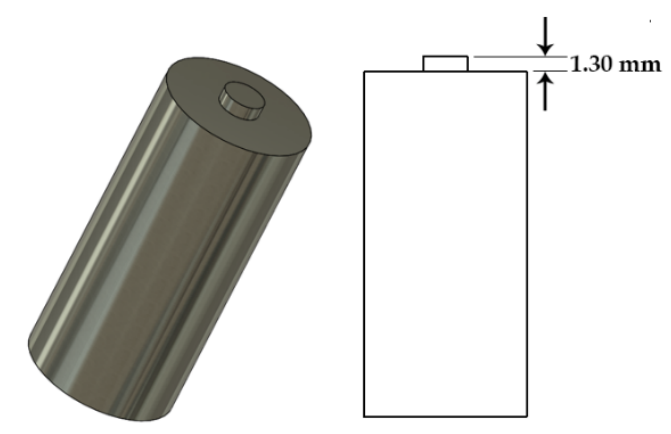

Fig. 1 The geometry of the WC tool

In this investigation, LDH test was employed to examine the formability of the welded sheets. A mandrel descending at $2 \mathrm{~mm} \cdot \mathrm{min}^{-1}$ was used for this test ${ }^{2)}$. When the sheet was torn, it resulted in drop of the force index indicator of the device. At this stage, the applied force onto the mandrel was removed. In this situation, the moving distance of the mandrel is equal to the maximum formability limit of the sheet.

Forming limit diagrams (FLDs) were employed to investigate the formability of joints based on ASTM E 2218 standard $^{14)}$. For this test, sheets welded by optimized parameters were used. These $0.1 \mathrm{~mm}$ thick sheets with the diameters of 0.1 and $5 \mathrm{~mm}$ and center-to-center distance of $5 \mathrm{~mm}$ were manually extracted from the $1.5 \mathrm{~mm}$ thick welded sheets by a circular pattern. In this research, the major and minor engineering strains were calculated using ${ }^{12,14)}$ :

$$
\begin{aligned}
& \text { Major Strain }\left(e_{1}\right)(\%)=\frac{L_{f}-L_{0}}{L_{0}} \times 100 \\
& \text { Minor Strain }\left(e_{2}\right)(\%)=\frac{W_{f}-W_{0}}{W_{0}} \times 100
\end{aligned}
$$

where $L_{o}$ is the initial length, $L_{f}$ is the final length, $W_{o}$ is the initial width, and $\mathrm{W}_{\mathrm{f}}$ is the final width.

In response surface methodology (RSM), the response resulted from changing effective parameters while keeping control parameters constant is monitored. In this study, tensile strength was considered as the response while rotation speed, advancing/traverse speed, pin diameter, and shoulder diameter were the effective parameters. After evaluating 36 welded samples with the parameters shown in Fig. 2, it was found that sound welds can only be attained when the tool rotation speeds is $500-1000 \mathrm{rpm}$ and advancing speeds is 31.5 $160 \mathrm{~mm} \cdot \mathrm{min}^{-1}$. Based on these tests and data gathered

Table 1 Chemical composition of EN 10130 steel

\begin{tabular}{|c|c|c|c|c|c|c|c|c|c|c|c|c|c|c|}
\hline Element & $\mathrm{C}$ & $\mathrm{Si}$ & $\mathrm{Mn}$ & $\mathrm{P}$ & $\mathrm{S}$ & $\mathrm{Ni}$ & $\mathrm{Mo}$ & $\mathrm{Cu}$ & $\mathrm{V}$ & $\mathrm{W}$ & $\mathrm{Co}$ & $\mathrm{Al}$ & $\mathrm{Sn}$ & $\mathrm{Pb}$ \\
\hline wt. $\%$ & 0.04 & 0.01 & 0.23 & 0.007 & 0.006 & 0.03 & 0.01 & 0.03 & 0.002 & 0.003 & 0.004 & 0.05 & 0.007 & 0.003 \\
\hline
\end{tabular}




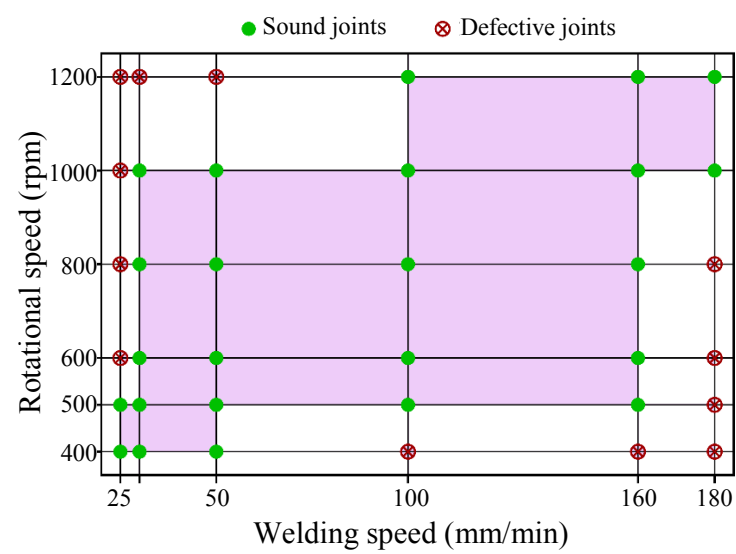

Fig. 2 Lower and upper levels of linear advancing and tool rotation speeds showing the experimental design zone in pink. Reproduced from ${ }^{13)}$ with permission from Journal of Solid Mechanics in Engineering

Table 2 Upper, intermediate, and lower levels of examined factors

\begin{tabular}{|c|c|c|c|}
\hline Parameters & $\begin{array}{c}\text { Lower } \\
\text { level }\end{array}$ & $\begin{array}{c}\text { Intermediate } \\
\text { level }\end{array}$ & $\begin{array}{c}\text { Upper } \\
\text { level }\end{array}$ \\
\hline Rotation speed $(\mathrm{rpm})$ & 500 & 750 & 1000 \\
\hline Traverse speed $\left(\mathrm{mm} \cdot \mathrm{min}^{-1}\right)$ & 31.5 & 95 & 160 \\
\hline Shoulder diameter $(\mathrm{mm})$ & 13.5 & 14.5 & 15.5 \\
\hline Pin diameter $(\mathrm{mm})$ & 2.5 & 3.5 & 4.5 \\
\hline
\end{tabular}

from previous studies ${ }^{1,8,12,15,16)}$, the upper, intermediate, and lower levels were selected (Table 2). DOE was done by Design-Expert software via Box-Behnken design with 5 center points. Table 3 displays 29 runs along with their obtained ultimate tensile strength (UTS) as the response.

\section{Results and discussion}

The effects of rotation and advancing speeds on joint strength are evident in Fig. 3a. As reported by other researchers ${ }^{16,17)}$, rotation speed has a higher influence on joint strength as compared with the advancing speed. According to this figure, the highest strength can be gained with a rotation speeds of 700 to $875 \mathrm{rpm}$ and advancing speeds of 60 to $90 \mathrm{~mm} \cdot \mathrm{min}^{-1}$. According to Fig. 3a-f, in terms of their effect on the response, parameters can be sorted as tool rotation speed, advancing speed, pin diameter, and shoulder diameter. The sufficiency of the DOE model is investigated and the result is presented in Table 4.

\subsection{Metallography and microstructural examinations}

Fig. 4 a shows the microstructure of EN 10130 steel
Table 3 Designed experiments by Box-Behnken method and ultimate tensile strength results in tensile test

\begin{tabular}{|c|c|c|c|c|c|}
\hline $\begin{array}{c}\text { Run } \\
\text { No. }\end{array}$ & $\begin{array}{c}\text { Shoulder } \\
\text { diameter }(\mathrm{mm})\end{array}$ & $\begin{array}{c}\text { Pin diameter } \\
(\mathrm{mm})\end{array}$ & $\begin{array}{c}\text { Traverse speed } \\
(\mathrm{mm} . \mathrm{min}-1)\end{array}$ & $\begin{array}{c}\text { Rotation } \\
\text { speed }(\mathrm{rpm})\end{array}$ & $\begin{array}{c}\text { UTS } \\
(\mathrm{MPa})\end{array}$ \\
\hline 1 & 14.5 & 3.5 & 95 & 750 & 292 \\
\hline 2 & 15.5 & 3.5 & 95 & 1000 & 261 \\
\hline 3 & 15.5 & 3.5 & 31.5 & 750 & 295 \\
\hline 4 & 15.5 & 3.5 & 160 & 750 & 159 \\
\hline 5 & 14.5 & 3.5 & 31.5 & 500 & 132 \\
\hline 6 & 14.5 & 3.5 & 31.5 & 1000 & 155 \\
\hline 7 & 14.5 & 4.5 & 31.5 & 750 & 290 \\
\hline 8 & 13.5 & 3.5 & 95 & 500 & 84 \\
\hline 9 & 13.5 & 3.5 & 31.5 & 750 & 302 \\
\hline 10 & 14.5 & 3.5 & 160 & 1000 & 293 \\
\hline 11 & 14.5 & 4.5 & 160 & 750 & 122 \\
\hline 12 & 13.5 & 2.5 & 95 & 750 & 279 \\
\hline 13 & 13.5 & 4.5 & 95 & 750 & 274 \\
\hline 14 & 14.5 & 4.5 & 95 & 500 & 89 \\
\hline 15 & 13.5 & 3.5 & 95 & 1000 & 284 \\
\hline 16 & 14.5 & 3.5 & 95 & 750 & 289 \\
\hline 17 & 14.5 & 3.5 & 95 & 750 & 292 \\
\hline 18 & 13.5 & 3.5 & 160 & 750 & 126 \\
\hline 19 & 14.5 & 4.5 & 95 & 1000 & 276 \\
\hline 20 & 15.5 & 3.5 & 95 & 500 & 109 \\
\hline 21 & 14.5 & 2.5 & 31.5 & 750 & 298 \\
\hline 22 & 15.5 & 4.5 & 95 & 750 & 281 \\
\hline 23 & 14.5 & 3.5 & 95 & 750 & 286 \\
\hline 24 & 14.5 & 2.5 & 95 & 500 & 96 \\
\hline 25 & 15.5 & 2.5 & 95 & 750 & 287 \\
\hline 26 & 14.5 & 3.5 & 160 & 500 & 80 \\
\hline 27 & 14.5 & 3.5 & 95 & 750 & 291 \\
\hline 28 & 14.5 & 2.5 & 95 & 1000 & 269 \\
\hline 29 & 14.5 & 2.5 & 160 & 750 & 131 \\
\hline
\end{tabular}

base metal. This microstructure contains about $2 \%$ pearlite and $98 \%$ ferrite. When welded sheets under optimized conditions (Table 4) were studied, it was observed that different zones with various characteristics were formed due to generated heat and plastic deformation. As demonstrated in Fig. $4 \mathrm{~b}$ as a result of welding 3 new zones are formed: (1) stir zone (SZ), thermo-mechanically affected zone (TMAZ), and heat affected zone (HAZ).

In SZ, grains which are 10-20 times finer and more homogenized than those of the base metal are formed. This is due to the recrystallization which occurs due to severe plastic deformation. According to literature ${ }^{18,19)}$, the temperature in $\mathrm{SZ}$ can reach 900 to $1100^{\circ} \mathrm{C}$. This, in conjunction with high severe plastic deformation, led to formation of fine and homogenized grains as a result of recrystallization. The plastic deformation increases the density of crystalline defects, especially dislocation 
(a)

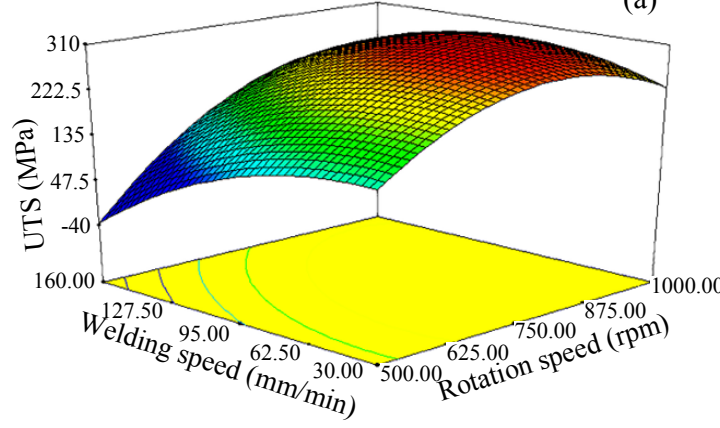

(c)

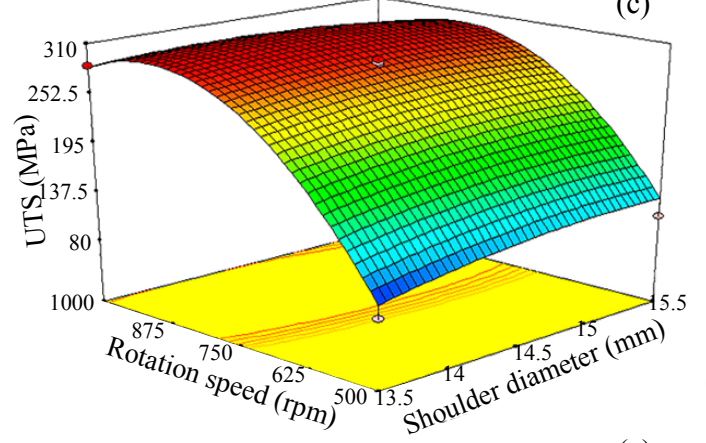

(e)

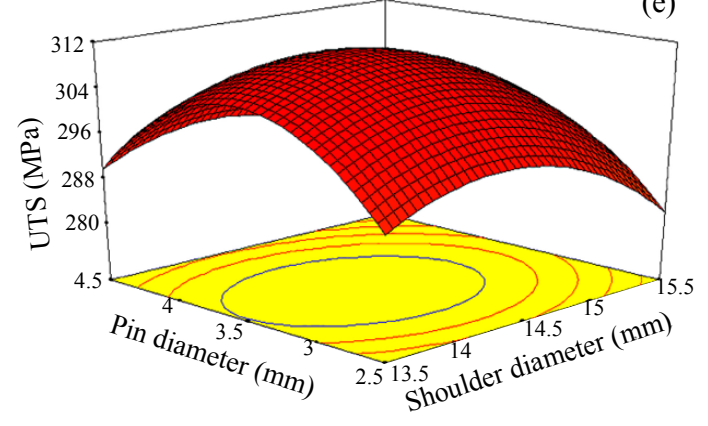

(b)

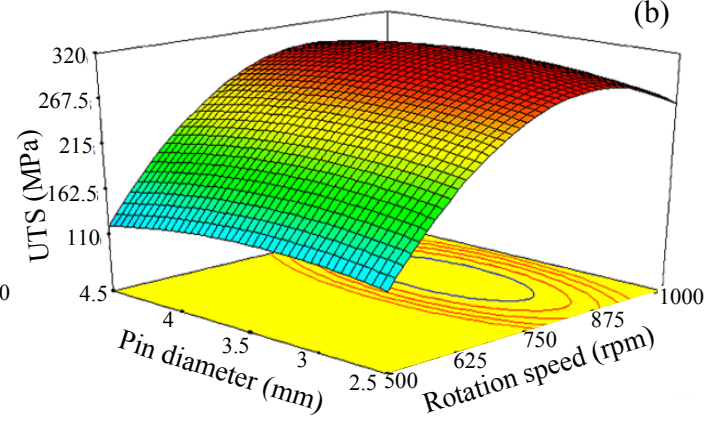

(d)

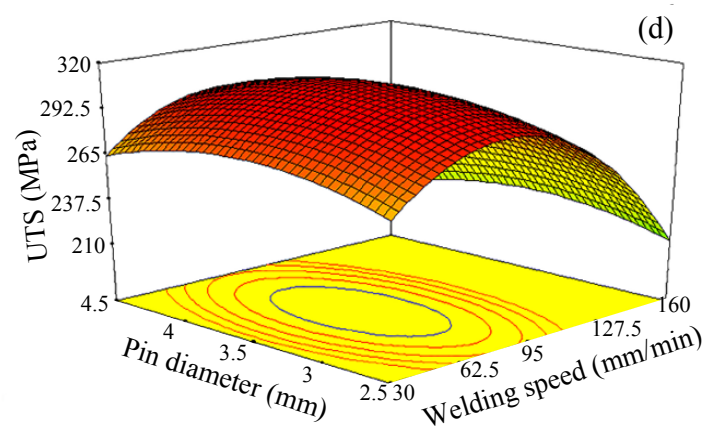

(f)

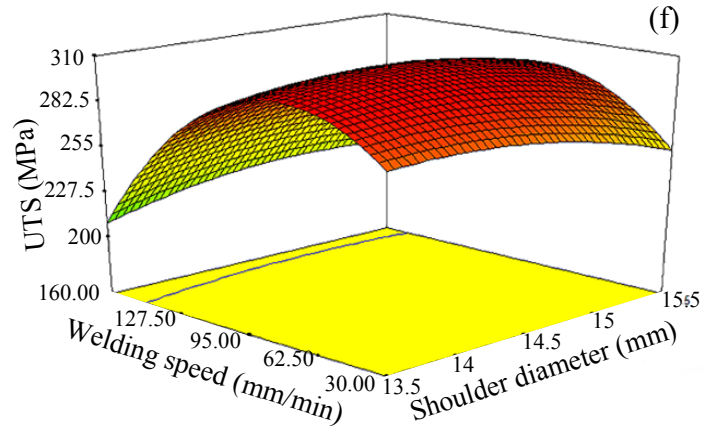

Fig. 3 Effect of different welding parameters on the tensile strength of welded sheets: (a) tool rotation speed and linear advancing speed, (b) tool rotation speed and pin diameter, (c) rotation speed and shoulder diameter, (d) tool linear advancing speed and pin diameter, (e) shoulder diameter and pin diameter, and (f) shoulder diameter and tool linear speed. (a) and (b) are reprinted from ${ }^{13)}$ with permission from Journal of Solid Mechanics in Engineering

Table 4 Predicted response by RSM and obtained experimental result

\begin{tabular}{|l|c|c|c|}
\cline { 3 - 4 } \multicolumn{2}{c|}{} & RSM & Experimental \\
\hline \multirow{4}{*}{$\begin{array}{l}\text { Optimized } \\
\text { parameter }\end{array}$} & Tool rotation speed (rpm) & 866 & 800 \\
\cline { 2 - 4 } & Pin diameter $(\mathrm{mm})$ & 3.92 & 3.9 \\
\cline { 2 - 4 } & Tool traverse speed $(\mathrm{mm} / \mathrm{min})$ & 78.74 & 80 \\
\cline { 2 - 4 } & Shoulder diameter $(\mathrm{mm})$ & 14.26 & 14.2 \\
\hline Response & UTS (MPa) & 308.3 & 305 \\
\hline
\end{tabular}

density. In the presence of high temperatures resulted from the friction between the tool and workpiece dynamic recrystallization becomes inevitable and new fine grains form resulting in increased hardness and strength ${ }^{20)}$.

SEM was used for better evaluation of the microstructure and the results are presented in Fig. 5. Due to the heating cycles, grains size in the HAZ is larger than that of the base metal. However, as a result of the thermomechanical cycles, the grain size in TMAZ is about two times smaller than the base metal. In comparison, SZ has very fine grains due to the dynamic recrystallization.

\subsection{Tensile properties}

The stress vs. strain curves for the base metal and the joint welded by optimized parameters are shown in Fig. 6 . The welded specimen fractured in base metal in the advancing side. However, the specimens welded by parameters out of the safe range were mostly fractured from the weld zone at much lower stresses and elongations.

\subsection{Microhardness measurement}

Fig. 7a shows the hardness profile of samples labeled as I, II, II, IV welded by parameters shown in Table 5. 

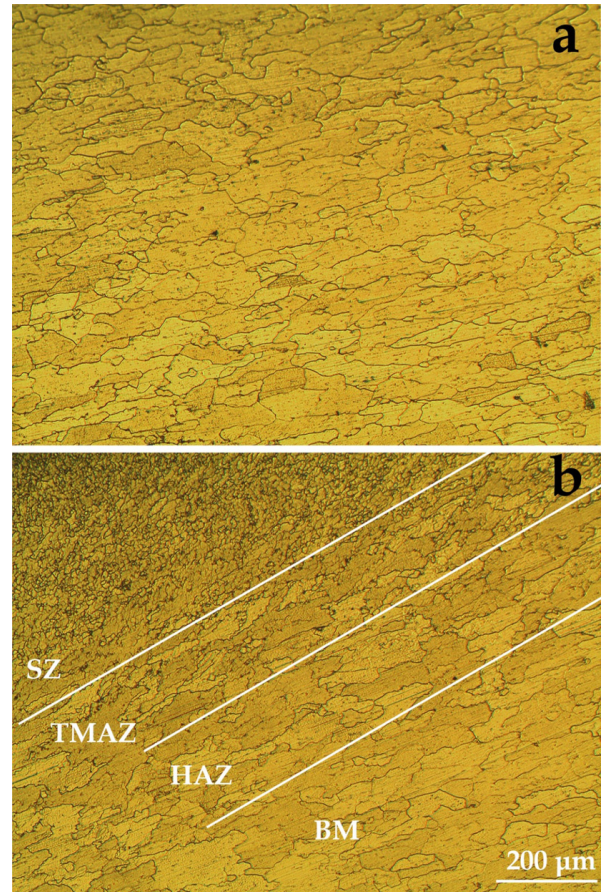

Fig. 4 Microstructure of (a) EN 10130 low-carbon steel base metal and (b) the joint welded by optimized parameters
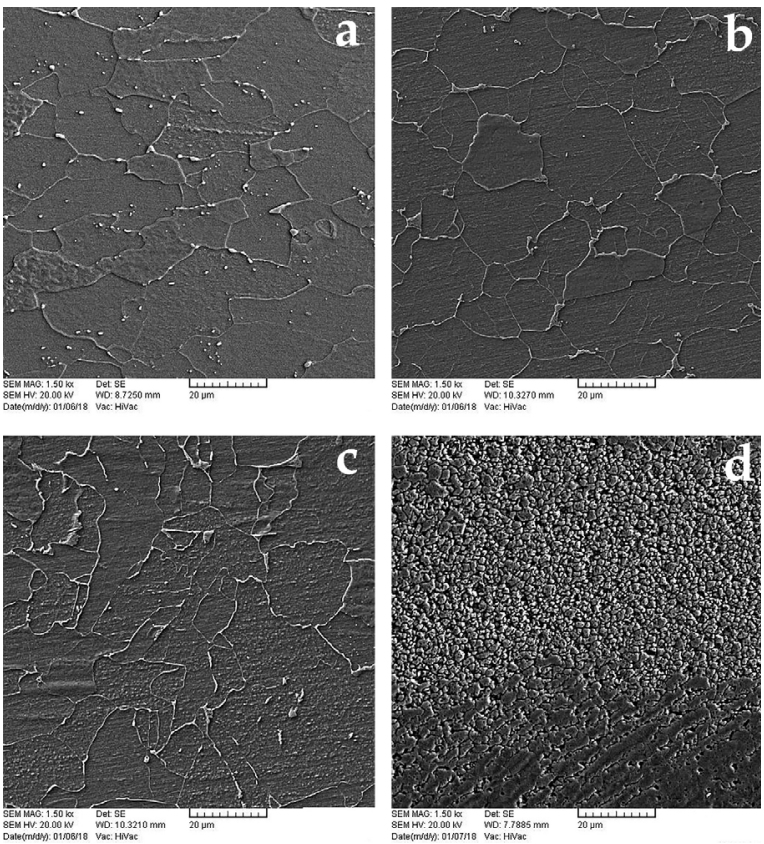

Fig. 5 SEM of different zones of welded joint: (a) base metal, (b) HAZ, (c) TMAZ, (d) SZ

All samples show a similar trend which is the increase of hardness from base metal to SZ flowing the microstructure of the regions discussed previously. The only exception is Sample I. This sample has the highest value of hardness in SZ. Previous studies ${ }^{1,8,21)}$ suggest sometimes enhanced local hardness in $\mathrm{SZ}$ can be due to

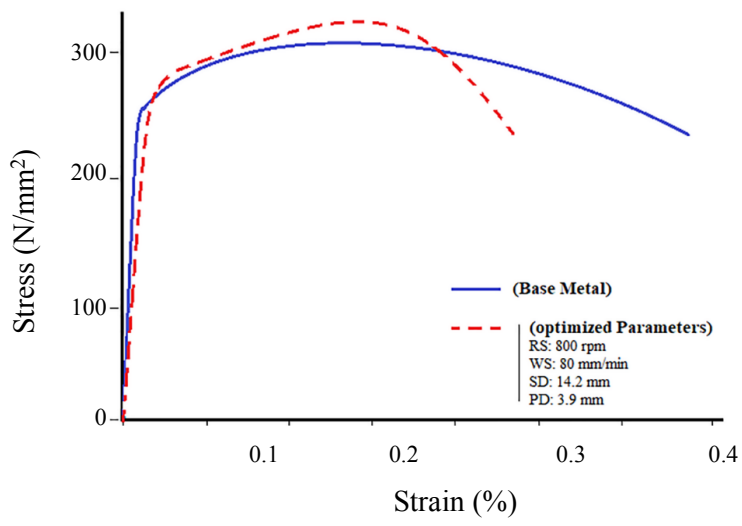

Fig. 6 Stress-strain diagrams of base metal and welded specimen with optimized parameters
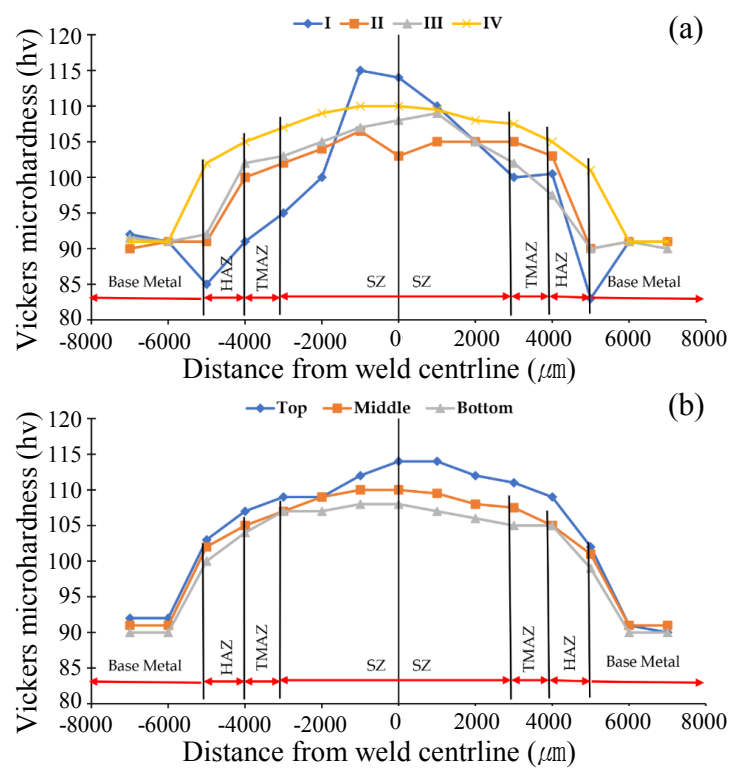

Fig. 7 Hardness measurements across the welded samples: (a) cross-section hardness profile of the friction stir butt joints I, II, III, and IV welded by parameters of Table 5; (b) profile of the upper, center, and bottom lines of sample IV

Table 5 Welding parameters for microhardness samples

\begin{tabular}{|c|c|c|c|}
\hline Sample & $\begin{array}{c}\text { Rotation } \\
\text { speed } \\
\text { (rpm) }\end{array}$ & $\begin{array}{c}\text { Traverse } \\
\text { speed } \\
\text { (mm/min) }\end{array}$ & $\begin{array}{c}\text { Summary of the welding } \\
\text { condition }\end{array}$ \\
\hline I & 1000 & 50 & High heat input \\
\hline II & 1000 & 100 & Parameters in the "safe" window \\
\hline III & 500 & 100 & Low heat input \\
\hline IV & 800 & 80 & $\begin{array}{c}\text { Optimized parameters obtained } \\
\text { through RSM }\end{array}$ \\
\hline
\end{tabular}

extremely high heat input followed by the detachment of tungsten carbide pieces and formation of iron/tungsten composites. Also, this sample has hardness values less than the base metal in the HAZ which is due to excessive heat input and grain coarsening. 
Fig. $7 \mathrm{~b}$ shows the hardness profiles at the bottom, center, and upper part of the same sample (sample IV). It is discussed in the literature ${ }^{15)}$ that hardness in the bottom of the sample is lower than center and upper parts because of different cooling rates; the top parts undergoes the fastest cooling and thus, has the highest hardness due to the finer grains.

\subsection{LDH test}

For this test, initially EN 10130 base metal sheet was tested. For this sample, the gage showed $45 \mathrm{~mm}$ upon tearing (Fig. 8a). Then, two sample welded using optimized parameters were tested in both face and bead sections (Fig. 8b and Fig. 8c). For these samples, the gage was $40 \mathrm{~mm}$. This amount of deformation compared to base metal confirms the efficiency of the welding process. As expected, tearing of the joined sheets welded with non-optimized parameters occurred in the nugget, as shown in Fig. 8d.

As confirmed by a recent study ${ }^{12)}$, Fig. 8 confirms that welding reduces ductility. This observation also endorses the stress-strain diagram in Fig. 6 where welded sample showed a lower ductility than the base metal.

\subsection{Forming limit diagrams}

To draw FLDs, circular signs which were completely or partially placed on the necked area were considered unacceptable and circles distanced equal or more than one diameter from necked area with no necking effect were considered as correct values, i.e. safe points. FLDs were drawn by interpolation of the safe points ${ }^{14}$. Circles placed in the necking area or in the adjacent

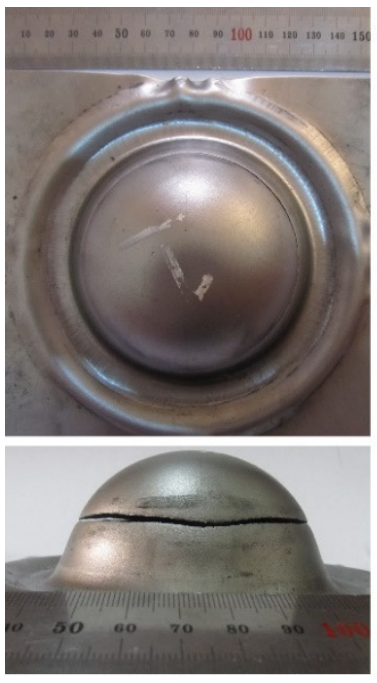

(a)

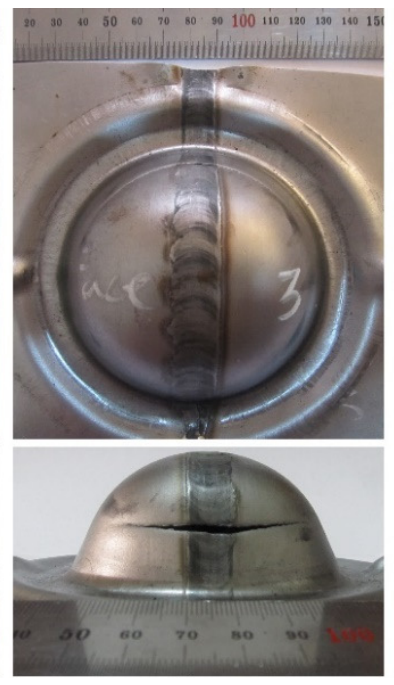

(b) torn area are displayed as unsafe points in these diagrams. Considering the fact that increasing thickness increases ductility and welding decreases $\mathrm{it}^{12,22)}$, it can be concluded that the value of $\mathrm{FLD}_{0}$ for EN 10130 base metal sheet with the thickness of $1.5 \mathrm{~mm}$ is higher than 0.48 of that of the welded sheet. Fig. 9 shows the FLD of EN 10130 sheets with $1.5 \mathrm{~mm}$ thickness used in this study. If the strain induced by FSW is above the forming limit curve in Fig. 10, the sheet will tear resulting in a defective weld.

\subsection{Effect of tool rotation and linear advancing speeds}

According to Terry's reports ${ }^{23}$, advancing speed should be changed together with rotation speed, otherwise defects, such as cavity and porosity, are created in the weld nugget.

According to Table 6, 20 experimental tests in the present study were carried out to evaluate the effect of simultaneous change of these two parameters. In these tests, the shoulder and pin diameter were constant at 14.2 and $3.9 \mathrm{~mm}$, respectively.

The results are presented in Fig. 11. As can be seen in Fig. 11a, the highest strength was reached within the range of 600-1000 rpm in any linear advancing speed except for $31.5 \mathrm{~mm} / \mathrm{min}$. Also, according to the Fig. $11 \mathrm{~b}$, at constant rotation speeds, the highest and lowest strengths were obtained at the rotation speed of 50 and $160 \mathrm{~mm} \cdot \mathrm{min}^{-1}$, respectively. The reason is attributed to different generated heat rates and amounts of mechanical work in the joint ${ }^{2}$.

As shown in Fig. 11b, in the range $50-100 \mathrm{~mm} \cdot \mathrm{min}^{-1}$, advancing speed provides a suitable friction in the weld region. Too much friction and, consequently, too high

Fig. 8 Samples for LDH test: (a) raw EN 10130 sheet; (b) face of welded sample under optimized parameters; (c) bead of sample welded under optimized parameters, and (d) welded sample under non-optimized parameters 

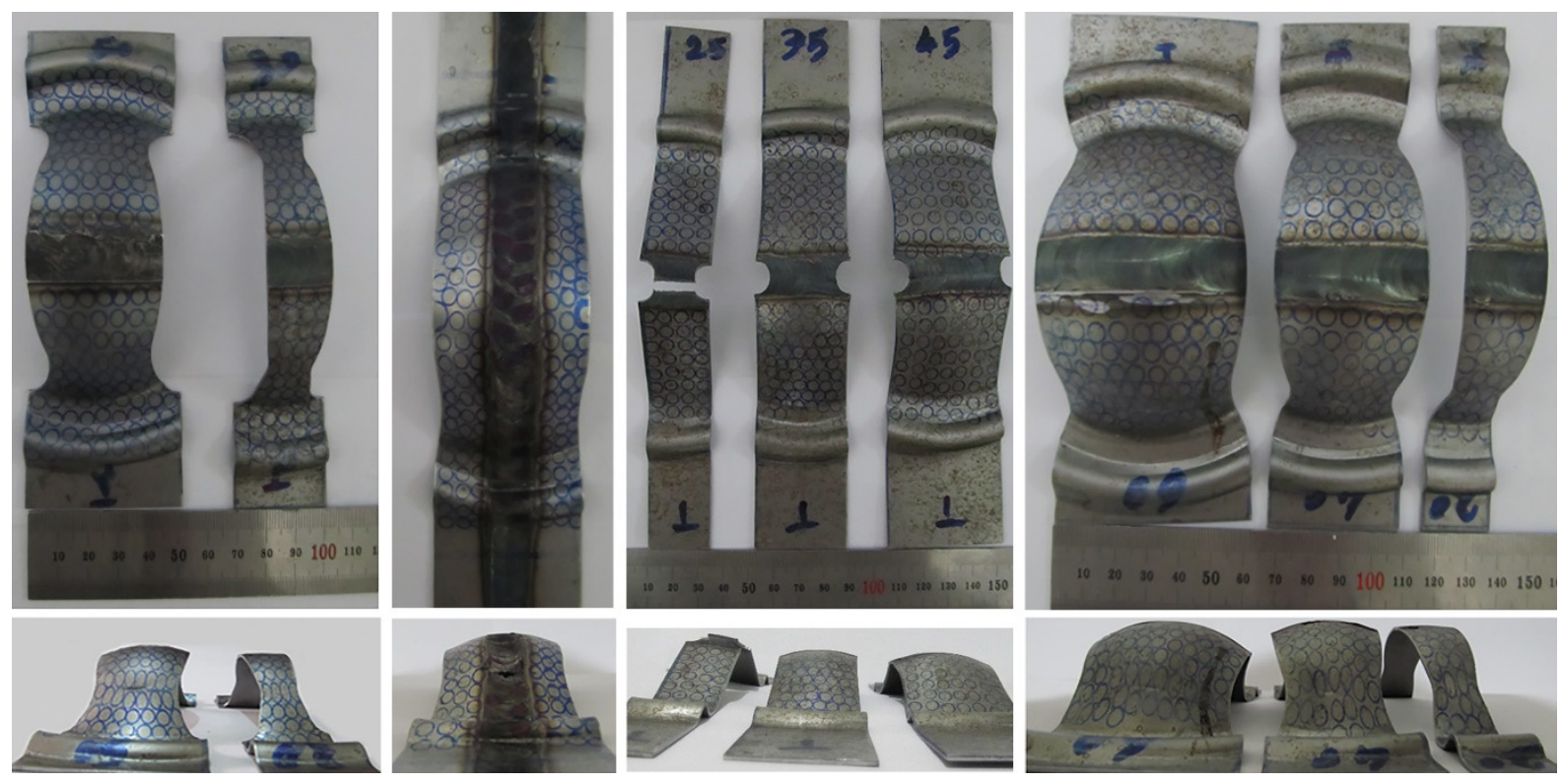

Fig. 9 FLD samples used for determining the minor and major principal strains

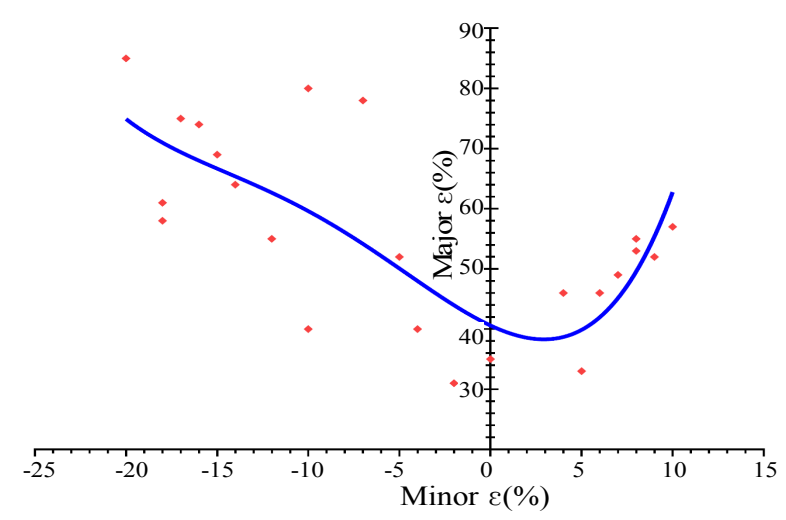

Fig. 10 FLD of EN 10130 steel sheets with thickness of $1.5 \mathrm{~mm}$ welded by FSW

heat inputs can cause grain coarsening and formation of porosities due to high plastic flow ${ }^{24)}$. Thus, the cause of low strength in advancing speeds lower than $50 \mathrm{~mm} \cdot \mathrm{min}^{-1}$ can be attributed to the high heat input and formation of the mentioned defects.

According to Fig. 11a, at a constant rotation speed (except for $500 \mathrm{rpm}$ ), the highest strength was obtained at a linear advancing speed within 50-100 mm.min ${ }^{-1}$ range. Thus, it can be concluded that the samples welded with tool rotation speed of 600-1000 rpm and advancing speed of $50-100 \mathrm{~mm} / \mathrm{min}$ have the maximum tensile strength. Optimized parameters by DOE experimental design were in this range, as shown in spot A of Fig. 12. These results approve the validation of selected factors, experimental design, obtained mathematical function, and more importantly, the optimization process.
Table 6 Experimental tests designed to determine the relationship between rotation and advancing speeds

\begin{tabular}{|c|c|c|c|}
\hline No. & $\begin{array}{c}\text { Rotation speed } \\
(\mathrm{rpm})\end{array}$ & $\begin{array}{c}\text { Traverse speed } \\
(\mathrm{mm} / \mathrm{min})\end{array}$ & $\begin{array}{c}\text { UTS } \\
(\mathrm{MPa})\end{array}$ \\
\hline 1 & 500 & 31.5 & 132 \\
\hline 2 & 500 & 50 & 98 \\
\hline 3 & 500 & 100 & 91 \\
\hline 4 & 500 & 160 & 80 \\
\hline 5 & 600 & 31.5 & 190 \\
\hline 6 & 600 & 50 & 182 \\
\hline 7 & 600 & 100 & 162 \\
\hline 8 & 600 & 160 & 140 \\
\hline 9 & 800 & 31.5 & 295 \\
\hline 10 & 800 & 50 & 298 \\
\hline 11 & 800 & 100 & 290 \\
\hline 12 & 800 & 160 & 257 \\
\hline 13 & 1000 & 31.5 & 155 \\
\hline 14 & 1000 & 50 & 270 \\
\hline 15 & 1000 & 100 & 294 \\
\hline 16 & 1000 & 160 & 275 \\
\hline 17 & 1200 & 31.5 & 140 \\
\hline 18 & 1200 & 50 & 245 \\
\hline 19 & 1200 & 100 & 265 \\
\hline 20 & 1200 & 160 & 260 \\
\hline & & & \\
\hline
\end{tabular}

\section{Conclusions}

Welding parameters for joining EN 10130 low-carbon steel by FSW were optimized, and the following results were obtained:

- The coarse-grain microstructure of the base metal 


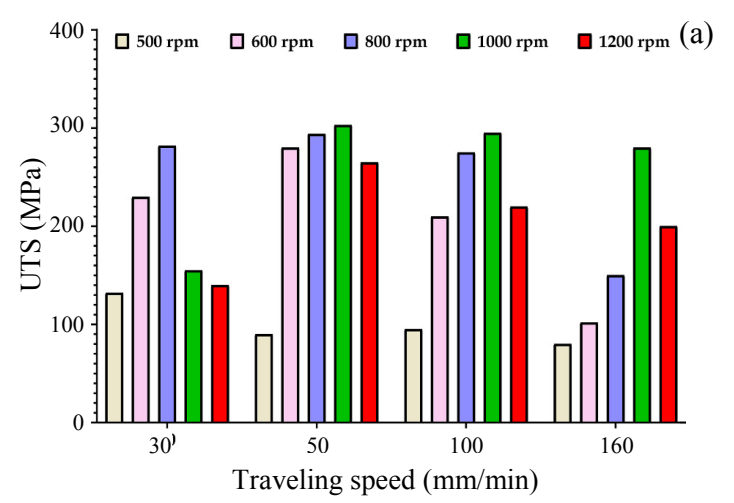

(b)

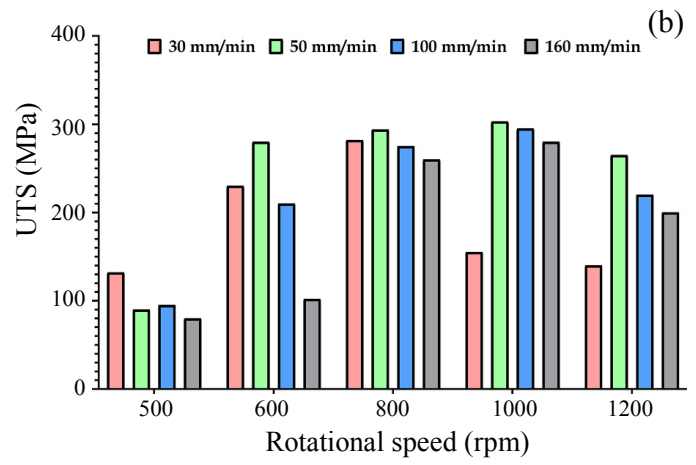

Fig. 11 UTS versus (a) various advancing speeds at constant rotation speed and (b) rotation speeds at constant advancing speed

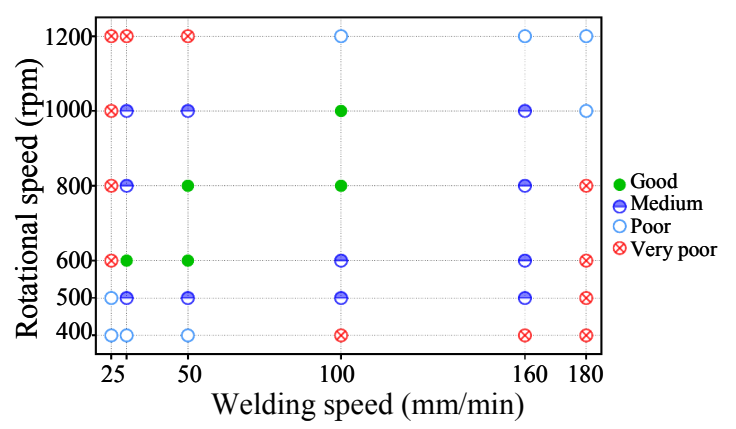

Fig. 12 "Safe" ranges for rotation and advancing speeds

was turned into a fine microstructure with coaxial grains as a result of FSW.

- As a result of recrystallization, the stir zone showed higher tensile strength and hardness compared with the base metal.

- The optimized FSW parameters for welding $1.5 \mathrm{~mm}$ thick EN10130 sheets using a pin with $1.3 \mathrm{~mm}$ pin height were $14.2 \mathrm{~mm}$ shoulder diameter, $3.9 \mathrm{~mm}$ pin diameter, $800 \mathrm{rpm}$ rotation speed, and $80 \mathrm{~mm} / \mathrm{min}$ advancing speed.

- Using limiting dome height, forming limit diagram and accordingly the maximum allowable FSW-induced strain showing the safe ranges for the two most important parameters, i.e. rotation and advancing speeds, were determined. Welding within this safe parameter space will not result in any defective joint.

ORCID: Akbar Alimohamady: http://orcid.org/0000-0003-1827-2517

ORCID: Abbas Eghlimi: http://orcid.org/0000-0003-3178-8147

ORCID: Mohammad Alipour Behzadi: hittp:/orcid.org/0000-0003-1798-8986

ORCID: Javad Mohammadi: https://orcid.org/0000-0003-0333-9889

\section{References}

1. M. B. Bilgin and C. Meran, The effect of tool rotational and traverse speed on friction stir weldability of AISI 430 ferritic stainless steels, Mater. Des. 33 (2012) 376383. https://doi.org/10.1016/j.matdes.2011.04.013

2. M. Ghaffarpour, M. Kazemi, M. J. Mohammadi Sefat, A. Aziz and K. Dehghani, Evaluation of dissimilar joints properties of 5083-H12 and 6061-T6 aluminum alloys produced by tungsten inert gas and friction stir welding, J. Mater. : Des. Appl. 231(3) (2017) 297-308. https://doi.org/10.1177/1464420715595652

3. R. Pouriamanesh and K. Dehghani, Micro Structure and Hardness of Steel- $\mathrm{TiO}_{2}$ Composite produced by Friction Stir Welding, Indian J. Sci. Technol. Composite, Friction Stir Welding (FSW), Hardness Microstructure 11(8) (2018).

http://dx.doi.org/10.17485/ijst\%2F2018\%2Fv11i8\%2F118567

4. K. P. Mehta and V. J. Badheka, Effects of Tool Pin Design on Formation of Defects in Dissimilar Friction Stir Welding, Proc. Technol. 23 (2016) 513-518. https://doi.org/10.1016/j.protcy.2016.03.057

5. R. Padmanaban, V. Balusamy, V. Saikrishna, and K. G. Niranthar, Simulated Annealing Based Parameter Optimization for Friction Stir Welding of Dissimilar Aluminum Alloys, Proc. Eng. 97 (2014) 864-870. https://doi.org/10.1016/j.proeng.2014.12.361

6. M. Fazel-Najafabadi, S. F. Kashani-Bozorg and A. ZareiHanzaki, Joining of CP-Ti to 304 stainless steel using friction stir welding technique, Materi. Des. 31(10) (2010) 4800-4807. https://doi.org/10.1016/j.matdes.2010.05.003

7. L. Giraud, H. Robe, C. Claudin, C. Desrayaud, P. Bocher, and $\mathrm{E}$. Feulvarch, Investigation into the dissimilar friction stir welding of AA7020-T651 and AA6060-T6, J. Mater. Process Technol. 235 (2016) 220-230. https://doi.org/10.1016/j.jmatprotec.2016.04.020

8. M. Jafarzadegan, A. H. Feng, A. Abdollah-zadeh, T. Saeid, J. Shen and H. Assadi, Microstructural characterization in dissimilar friction stir welding between 304 stainless steel and st37 steel, Mater. Charact. 74 (2012) 28-41. https://doi.org/10.1016/j.matchar.2012.09.004

9. A. Yazdipour and A. Heidarzadeh, Effect of friction stir welding on microstructure and mechanical properties of dissimilar Al 5083-H321 and 316L stainless steel alloy 
joints, JAllC, 680 (2016) 595-603.

https://doi.org/10.1016/j.jallcom.2016.03.307

10. R. Ramesh, I. Dinaharan, R. Kumar and E. T. Akinlabi, Microstructure and mechanical characterization of friction stir welded high strength low alloy steels, Mater. Sci. Eng. A, 687 (2017) 39-46. https://doi.org/10.1016/j.msea.2017.01.050

11. H. H. Cho, H. N Han, S. T. Hong, J. H. Park, Y. J. Kwon, S. H. Kim and Russell. J. Steel, Microstructural analysis of friction stir welded ferritic stainless steel, Mater. Sci. Eng. A, 528(6) (2011) 2889-2894. https://doi.org/10.1016/j.msea.2010.12.061

12. M. Habibi, R. Hashemi, M. Fallah Tafti, and A. Assempour, Experimental investigation of mechanical properties, formability and forming limit diagrams for tailor- welded blanks produced by friction stir welding, J. Manuf. Processes. 31(2018) 310-323. https://doi.org/10.1016/j.jmapro.2017.11.009

13. A. Alimohammady, M. Kasiri Asgarani, M. Afrand and H. Noruzi Forooshani, Optimization of the parameters of low-carbon steel (EN10130) welding using friction stir welding method, J. Solid Mech. Eng. 9(4) 603-612.

14. Standard No??. Standard Test Method for Determining Forming Limit Curves, American Society for Testing Materials (ASTM), (2015).

15. Y. D. Chung, H. Fujii, Y. Sun and H. Tanigawa, Interface microstructure evolution of dissimilar friction stir butt welded F82H steel and SUS304, Mater. Sci. Eng. A, 528(18) (2011) 5812-5821. https://doi.org/10.1016/j.msea.2011.04.023

16. T. Källgren, Friction Stir Welding of Copper Canisters for Nuclear Waste, Teknologie Licentiat, Department of Materials Science and Engineering, Royal Institute of Technology (KTH), Stockholm, Sweden, (2005).
17. S. Rajakumar and V. Balasubramanian, Establishing relationships between mechanical properties of aluminium alloys and optimised friction stir welding process parameters, Mater. Des. 40 (2012) 17-35. https://doi.org/10.1016/j.matdes.2012.02.054

18. M. Jafarzadegan, A. Abdollah-zadeh, A. H. Feng, T. Saeid, J. Shen and H. Assadi, Microstructure and Mechanical Properties of a Dissimilar Friction Stir Weld between Austenitic Stainless Steel and Low Carbon Steel, J. Mater. Sci. Technol. 29(4) (2013) 367-372. https://doi.org/10.1016/j.jmst.2013.02.008

19. M. Ghosh, K. Kumar, and R. S. Mishra, Friction stir lap welded advanced high strength steels: Microstructure and mechanical properties, Materi. Sci. Eng. A, 528(28) (2011) 8111-8119. https://doi.org/10.1016/j.msea.2011.06.087

20. L. Fratini, G. Buffa, and R. Shivpuri, Improving friction stir welding of blanks of different thicknesses, Mater. Sci. Eng. A, 459(1) (2007) 209-215. https://doi.org/10.1016/j.msea.2007.01.041

21. T. J. Lienert, J. Stellwag, W.L., B. B. Grimmett, and R. W. Warke, Friction Stir Welding Studies on Mild Steel, Suppl. Weld. J. (2003) 1s-9s.

22. M. Abbasi, S. R. Hamzeloo, M. Ketabchi, M. A. Shafaat and B. Bagheri, Analytical method for prediction of weld line movement during stretch forming of tailorwelded blanks, Int. J. Adv. Manuf. Technol. 73(5) (2014) 999-1009. https://doi.org/10.1007/s00170-014-5850-3

23. T. Khaled, An Outsider Looks at Friction Stir Welding, Federal Aviation Administration, Lakewood, CA, (2005).

24. A. K. Lakshminarayanan, Enhancing the properties of friction stir welded stainless steel joints via multi-criteria optimization, Arch. Civ. Mech. Eng. 16(4) (2016) 605-617. https://doi.org/10.1016/j.acme.2016.03.012 